ACCEPTED MANUSCRIPT

\title{
Boosted Ultraviolet Photodetection of AIGaN Quantum-Disk Nanowires via Rational Surface Passivation
}

To cite this article before publication: Chen Huang et al 2021 J. Phys. D: Appl. Phys. in press https://doi.org/10.1088/1361-6463/ac4185

\section{Manuscript version: Accepted Manuscript}

Accepted Manuscript is "the version of the article accepted for publication including all changes made as a result of the peer review process, and which may also include the addition to the article by IOP Publishing of a header, an article ID, a cover sheet and/or an 'Accepted

Manuscript' watermark, but excluding any other editing, typesetting or other changes made by IOP Publishing and/or its licensors"

This Accepted Manuscript is @ 2021 IOP Publishing Ltd.

During the embargo period (the 12 month period from the publication of the Version of Record of this article), the Accepted Manuscript is fully protected by copyright and cannot be reused or reposted elsewhere.

As the Version of Record of this article is going to be / has been published on a subscription basis, this Accepted Manuscript is available for reuse under a CC BY-NC-ND 3.0 licence after the 12 month embargo period.

After the embargo period, everyone is permitted to use copy and redistribute this article for non-commercial purposes only, provided that they adhere to all the terms of the licence https://creativecommons.org/licences/by-nc-nd/3.0

Although reasonable endeavours have been taken to obtain all necessary permissions from third parties to include their copyrighted content within this article, their full citation and copyright line may not be present in this Accepted Manuscript version. Before using any content from this article, please refer to the Version of Record on IOPscience once published for full citation and copyright details, as permissions will likely be required. All third party content is fully copyright protected, unless specifically stated otherwise in the figure caption in the Version of Record.

View the article online for updates and enhancements. 


\title{
Boosted Ultraviolet Photodetection of AlGaN Quantum-Disk Nanowires via Rational Surface Passivation
}

\author{
Chen Huang ${ }^{1}$, Fangzhou Liang ${ }^{1}$, Huabin $\mathrm{Yu}^{1}$, Meng Tian ${ }^{1}$, Haochen Zhang ${ }^{1}$, Tien \\ Khee $\mathrm{Ng}^{2}$, Boon S. Ooi ${ }^{2}$ and Haiding Sun ${ }^{1}$ \\ ${ }^{1}$ School of Microelectronics, University of Science and Technology of China, Hefei, Anhui, 230026, \\ China \\ ${ }^{2}$ Computer, Electrical, and Mathematical Sciences and Engineering Division, King Abdullah University \\ of Science and Technology (KAUST), Thuwal 23955-6900, Saudi Arabia
}

E-mail: haiding@ustc.edu.cn

Received xxxxxx

Accepted for publication $\mathrm{xxxxxx}$

Published xxxxxx

\section{Abstract}

Self-assembled AlGaN nanowires (NWs) are regarded as promising structures in the pursuit of ultraviolet photodetectors (UV PDs). However, AlGaN nanowire-based PDs currently suffer from degraded performance partially owing to the existence of outstanding surfacerelated defects/traps as a result of its large surface-to-volume-ratio feature. Here, we propose an effective passivation approach to suppress such surface states via tetramethyl ammonium hydroxide (TMAH) solution treatment. We successfully demonstrate a fabrication of UV PDs using TMAH-passivated AlGaN quantum-disk NWs and investigate their optical and electrical properties. Particularly, the dark current can be significantly reduced by an order of magnitude after surface passivation, thus leading to the improvement of photoresponsivity and detectivity. The underlying mechanism for such boost can be ascribed to the effective elimination of oxygen-related surface states on the nanowire surface. Consequently, an AlGaN nanowire UV PD with a low dark current of $6.22 \times 10^{-9} \mathrm{~A}$, a large responsivity of 0.95 $\mathrm{A} \mathrm{W}^{-1}$, and a high detectivity of $6.4 \times 10^{11}$ Jones has been achieved.

Keywords: AlGaN nanowires, ultraviolet photodetectors, dark current, passivation, tetramethyl ammonium hydroxide, surface states

\section{Introduction}

Searching for highly efficient, compact, and low-powerconsumption ultraviolet photodetectors (UV PDs) (for example, photoelectrochemical-type PDs [1,2] and solidstate PDs [3]) has become significantly essential due to the increasing demands for advanced applications in military and civil fields, including space exploration, missile monitoring, fire alarm, and secure communication. The III-nitride semiconductors, particularly, the $\mathrm{Al}_{\mathrm{x}} \mathrm{Ga}_{1-\mathrm{x}} \mathrm{N}$ alloys possessing a wide bandgap ranging from $3.4 \mathrm{eV}$ to $6.1 \mathrm{eV}$ via tunning the Al composition, can cover the entire UV spectral range from $360 \mathrm{~nm}$ to $210 \mathrm{~nm}$ [4,5]. Additionally, the high carrier mobility, chemical robustness, and high thermal conductivity of AlGaN alloys make them one of the top contenders for the realization of high-performance UV PDs [6]. However, conventional planar AlGaN UV PDs still suffer from poor Al-rich AlGaN epilayer quality and low light absorption efficiency, which results in performance degradation when 
the detection wavelength moves toward shorter wavelength $[7,8]$. Fortunately, the AlGaN nanowires (NWs), exhibiting many outstanding inherent properties relative to planar structures, have been considered as emerging structures to build AlGaN UV PDs. First of all, during the nanowire growth, the lateral strain can be effectively released because of the nearly infinite critical thickness in one-dimensional structures, thus the defect-free crystalline quality of a single AlGaN nanowire can be realized $[9,10]$. Secondly, the p-type doping efficiency in $\mathrm{AlGaN}$ NWs can be remarkably improved due to more efficient $\mathrm{Mg}$ incorporation and lower activation energy, which are caused by sufficient surface dopants and reduced lattice strain in nanowire structures $[11,12]$. Last but not least, the large surface-to-volume ratios and multiple light scattering effects in $\mathrm{AlGaN}$ NWs can enhance the light absorption efficiency [13]. Consequently, adopting AlGaN NWs has been regarded as an promising approach to fabricate high-performance UV PDs.

However, the development of AlGaN nanowire UV PDs is still in its infancy by two main challenges: the difficulty of nanowire-based device fabrication and the extensive surface states [9]. It is noted that a low filling factor of nanowire array will cause the metal penetration into the nanowire gaps so that the metal deposition during the electrode formation has to be carefully designed and optimized during the fabrication process [10]. Researchers have tried the planarization step using polyimide or parylene to fill the gaps before depositing metal pads. Unfortunately, the introduction of such polymer results in an undesirable increase in fabrication cost and time. It may also block the incidence of UV light and aggravate the heat accumulation, which may cause serious damage to the device operation $[14,15]$. To avoid this obstacle, we intentionally grew the nearly coalesced NWs, on which we can directly deposit metal pads without using any filling materials, simplifying the fabrication process [16]. On the other side, the presence of a large number of surface states (such as dangling bonds and surface defects) on the nanowire surface can introduce the Shockley-Read-Hall (SRH) nonradiative recombination centers, which will capture the photoexcited carriers and lower the quantum efficiency of photodetection devices $[17,18]$. Many efforts have been dedicated to removing such surface states to suppress surface recombination for performance improvement. In particular, surface treatment using various wet chemicals has been proved to be an effective method to passivate defect-related surface states. Zhao et al. reported the successful mitigation of SRH recombination by octadecyl thiol (ODT) and inorganic sulfide passivation in InGaN/GaN disk-in-nanowire lightemitting diodes (LEDs) [17]. Moreover, Sun et al. introduced the potassium hydroxide $(\mathrm{KOH})$ solution treatment as an additional passivation process to achieve significantly enhanced luminescence performance of $\mathrm{AlGaN}$ nanowire
LEDs [19]. Bui et al. used ammonium sulfide $\left(\left(\mathrm{NH}_{4}\right)_{2} \mathrm{~S}_{\mathrm{x}}\right)$ to passivate the p-i-n AlGaN nanowire LEDs and found that the electrical and optical properties of LED devices improved obviously after sufficient passivation [20]. However, limited studies and exploration on the effect of surface passivation on the performance of AlGaN nanowire-based UV PDs hàve been carried out so far.

In this work, we report on the fabrication of UV PDs using as-grown and passivated p-i-n AlGaN quantum-disk NWs grown by molecular beam epitaxy (MBE) on $\mathrm{Si}$ substrates. The surface passivation was performed by using the tetramethyl ammonium hydroxide (TMAH) solution, which is commonly used as a follow-up step after dry etching of GaN-based thin films to improve the sidewall roughness for light-emitting devices or to suppress the leakage current in the fabrication of power devices [21,22]. Here, we investigate the underlying TMAH passivation mechanism and its effects on the electrical and optical characteristics of $\mathrm{AlGaN}$ nanowire PDs. Surprisingly, passivated AlGaN nanowire PDs show much lower dark current and higher responsivity compared to the passivationfree devices. The further spectroscopic characterization provides strong evidence that surface defects and oxides can be effectively eliminated through simple TMAH wet passivation, thus enhancing the UV photodetection.

\section{Experimental section}

The AlGaN quantum-disk NWs studied in this work were grown on $\mathrm{n}-\mathrm{Si}$ (001) substrates using Veeco plasma-assisted MBE under nitrogen-rich conditions. Prior to the AlGaN nanowire growth, $\sim 50 \mathrm{~nm}$ Si-doped $\mathrm{n}$-GaN seeds were initiated at a substrate temperature of $550{ }^{\circ} \mathrm{C}$. The $\mathrm{Si}$ effusion cell was kept at $1180^{\circ} \mathrm{C}$, the $\mathrm{Ga}$ beam equivalent pressure (BEP) was $6.0 \times 10^{-8}$ Torr, and the high-brightness nitrogen plasma was sustained using $350 \mathrm{~W}$ RF power and $1 \mathrm{sccm}$ flow rate. The followed $p-i-n$ AlGaN structures were then grown at a higher temperature of $630^{\circ} \mathrm{C}$. We estimated the nominal $\mathrm{Al}$ composition based on the ratio of the $\mathrm{Al} \mathrm{BEP}$ to the total metal BEP as measured by the beam flux monitor. Around $150 \mathrm{~nm}$ Si-doped $\mathrm{n}-\mathrm{Al}_{0.4} \mathrm{Ga}_{0.6} \mathrm{~N}$ layers were firstly grown, followed by the active region consisting of 10 pairs $\mathrm{Al}_{0.25} \mathrm{Ga}_{0.75} \mathrm{~N} / \mathrm{Al}_{0.4} \mathrm{Ga}_{0.6} \mathrm{~N}$ quantum disk/quantum barrier with a thickness of $\sim 3$ and $\sim 6 \mathrm{~nm}$, respectively. Then $\sim 100 \mathrm{~nm}$ Mg-doped $\mathrm{p}-\mathrm{Al}_{0.4} \mathrm{Ga}_{0.6} \mathrm{~N}$ layers were grown under the $\mathrm{Mg}$ cell temperature of $360{ }^{\circ} \mathrm{C}$ with the same nitrogen plasma condition. Finally, the additional highly $\mathrm{Mg}$-doped p-GaN contact layers $(\sim 5 \mathrm{~nm})$ were deposited by increasing the $\mathrm{Mg}$ cell temperature to $380{ }^{\circ} \mathrm{C}$ at a reduced growth temperature of $580{ }^{\circ} \mathrm{C}$. The morphology of the $\mathrm{AlGaN}$ NWs was observed using field emission scanning electron microscopy (SEM) (SU8220, Hitachi) at an accelerating voltage of $3 \mathrm{kV}$. A schematic of the grown AlGaN nanowire structure and the 
corresponding SEM image of the vertically aligned nanowire arrays on $\mathrm{Si}$ are shown in figure 1(a) and figure1(b), respectively. We found that the coalesced NWs with relatively uniform height $(\sim 400 \mathrm{~nm})$ and diameter $(\sim 80 \mathrm{~nm})$ distribution exhibit a high filling factor $(>95 \%)$, indicating that we can directly deposit metal contacts on the top of the NWs. After the growth, samples were dipped into $25 \%$ TMAH at $50{ }^{\circ} \mathrm{C}$ for $30 \mathrm{~s}, 1 \mathrm{~min}, 2 \mathrm{~min}$, and $3 \mathrm{~min}$, respectively.
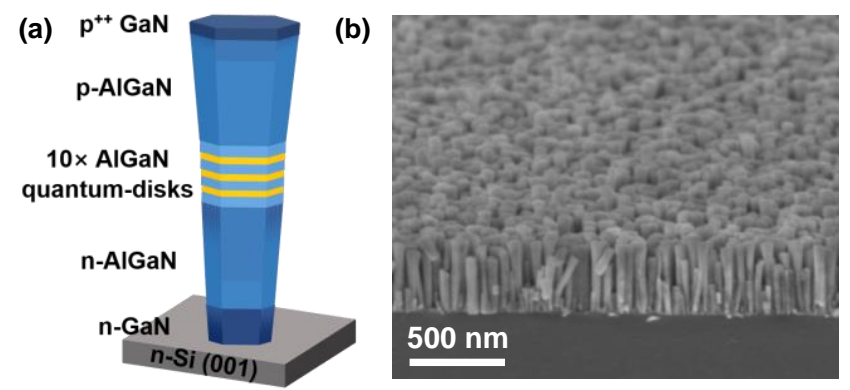

Figure 1. (a) The schematic structure of the $p-i-n$ AlGaN NWs on Si substrate. (b) A $20^{\circ}$-tilted SEM image of the $\mathrm{AlGaN}$ nanowire arrays.

To study the optical properties of the samples after TMAH treatment, room-temperature photoluminescence (PL) measurements were performed (using a $266 \mathrm{~nm}$ laser as the excitation source). The results are shown in figure 2 , it is noticed that the PL peak wavelength of the TMAH treated device exhibits a slight red-shift from $307.6 \mathrm{~nm}$ to $309.4 \mathrm{~nm}$. This phenomenon is consistent with our previous results and can be explained by the TMAH etching of Al-rich AlGaN shell coating on the nanowire surface [19]. More importantly, the peak PL intensity increases by around $80 \%$ (suggesting a significantly enhanced radiative recombination) using TMAH passivation method. We did not extend/the passivation time further, as the PL enhancement after 2 min was not significant (as shown in figure 2).

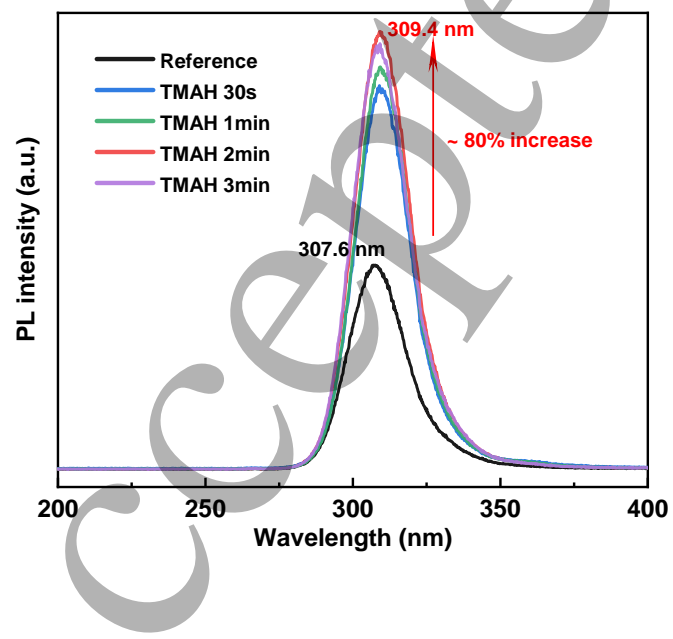

Figure 2. Room-temperature PL spectra of the samples with different TMAH passivation time.

We then fabricated the devices using standard UV contact lithography techniques. Every device size was defined/as $300 \times 300 \mu \mathrm{m}^{2}$. A Ni $(7.5 \mathrm{~nm}) / \mathrm{Au}(7.5 \mathrm{~nm})$ stacking metal layer was first deposited by electron-beam evaporation followed by rapid thermal annealing in a 4:1 $\mathrm{N}_{2}: \mathrm{O}_{2}$ ambient at $500{ }^{\circ} \mathrm{C}$ for $1 \mathrm{~min}$. A stack of $\mathrm{Ni}(20 \mathrm{~nm}) / \mathrm{Au}(50 \mathrm{~nm})$ was then deposited as the top pad for probing. Lastly, a thickness of $200 \mathrm{~nm}$ of Si was etched away from the Si backside using reactive-ion etching (RIE) and a $\mathrm{Ti}(20 \mathrm{~nm}) / \mathrm{Au}(50 \mathrm{~nm})$ metal layer was deposited as the n-pad, upon annealing under $\mathrm{N}_{2}$ ambient at $250{ }^{\circ} \mathrm{C}$ for $1 \mathrm{~min}$. The electrical performance of the PDs was tested by a semiconductor device analyzer (B1500A, Keysight). A $265 \mathrm{~nm}$ UV LED was applied as the illumination source and the light intensity was calibrated by an optical power meter (2936-R, Newport). TRPL spectra were measured by a time-correlated single-photon counting (TCSPC) system containing a femtosecond pulsed diode laser (PHAROS, Light Conversion, $\approx 221 \mathrm{fs}, 1030 \mathrm{~nm}, 50$ $\mathrm{kHz}, 10 \mathrm{~W}$ ), an optical parametric amplifier (ORPHEUS, Light Conversion, 190-2000 nm), a stand-along TCSPC module and a single photon counting photomultiplier. The average excitation power of the $235 \mathrm{~nm}$ laser on the sample surface was maintained to be $1 \mathrm{~mW}$ at a $50 \mathrm{kHz}$ repetition rate. XPS measurements were executed using an $\mathrm{Al} \mathrm{K \alpha} \mathrm{X}$ ray source of energy $1253.6 \mathrm{eV}$ (K-Alpha, Thermo Fisher Scientific).

\section{Results and discussion}

The current-voltage (I-V) characteristics of the reference and TMAH-treated samples under dark and $265 \mathrm{~nm}$ light illumination with a power density of $3.75 \mathrm{~mW} \mathrm{~cm}^{-2}$ are measured, as presented in figure 3(a). It is found that the dark current reduces by nearly an order of magnitude after TMAH passivation, from $7.23 \times 10^{-8} \mathrm{~A}$ to $6.22 \times 10^{-9} \mathrm{~A}$ at a bias of -4 $\mathrm{V}$. We have measured more than four devices on the TMAHtreated $\mathrm{AlGaN}$ nanowire PDs, and found that our devices exhibited nearly consistent dark currents in the range from $5.4 \times 10^{-9}$ to $9.5 \times 10^{-9} \mathrm{~A}$. This corroborates with previous observation during the optimization of PDs using other passivation methods $[18,23]$. Interestingly, the influence of such passivation on photocurrent enhancement is negligible. The photocurrents of the two devices increase to $2.86 \times 10^{-6} \mathrm{~A}$ and $3.21 \times 10^{-6} \mathrm{~A}$, respectively at $-4 \mathrm{~V}$ bias voltage. The value of responsivity $(R)$ is a critical feature indicator of PDs, which is given by $R=\left(I_{\text {photo }}-I_{\text {dark }}\right) /(P S)$, where $I_{\text {photo }}$ is the photocurrent, $I_{\text {dark }}$ is the dark current, $P$ denotes the light power density, and $S$ is the irradiated area of the device. After calculation, we find that after TMAH passivation, the $R$ 
of the AlGaN nanowire PD increases from $0.83 \mathrm{~A} \mathrm{~W}^{-1}$ to $0.95 \mathrm{~A} \mathrm{~W}^{-1}$ under $-4 \mathrm{~V}$ bias with the incident power density of $3.75 \mathrm{~mW} \mathrm{~cm}^{-2}$ at $265 \mathrm{~nm}$ light illumination.

The time-dependent photoresponse characteristics were measured under the same test conditions. As shown in figure 3(b), both devices exhibit reproducible and stable on/off switching behavior. By extracting the photo-to-dark-current ratio $\left(P D C R=\left(I_{\text {photo }}-I_{\text {dark }}\right) / I_{\text {dark }}\right)$, the TMAH-treated device shows a $P D C R$ of $\sim 500$, which is 10 times higher than that of the reference sample. This is attributed to the obviously reduced dark current in the passivated PDs. To evaluate the ability to detect the lowest detectable signal, the detectivity
$\left(D^{*}\right)$ defined as $D^{*}=R S^{1 / 2} /\left(2 q I_{\text {dark }}\right)^{1 / 2}$ were calculated to be $1.6 \times 10^{11}$ Jones for the reference device and $6.4 \times 10^{11}$ Jones for the passivated device, respectively. The rise and decay time $\left(t_{\text {rise }}\right.$, defined as the time for the current increasing from $10 \%$ to $90 \%$ of the peak value; $t_{\text {decay }}$, defined as the time for the current dropping from $90 \%$ to $10 \%$ of the peak value) of the two devices were also studied to judge the response speed of PDs to external photo source. Both devices exhibit fast response speed. Particularly, figure 3 (c) gives the $t_{\text {rise }}$ of $\sim 33$ $\mathrm{ms}$ and $t_{\text {decay }}$ of $\sim 27 \mathrm{~ms}$ in the passivated device (operated in $-4 \mathrm{~V}$ bias). (a)

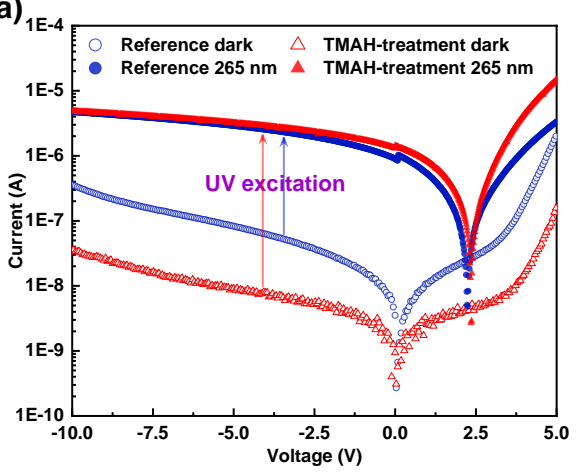

(b)

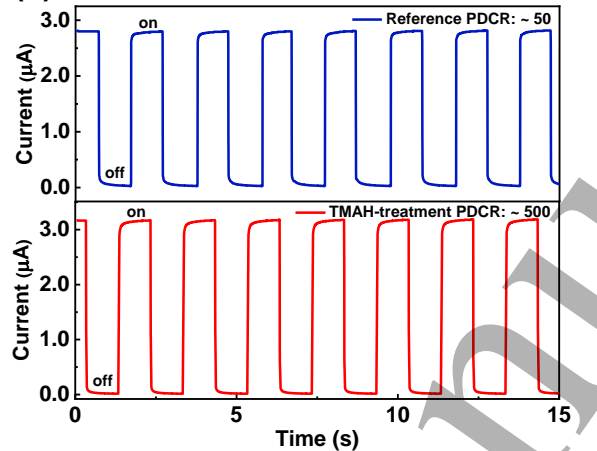

(c)

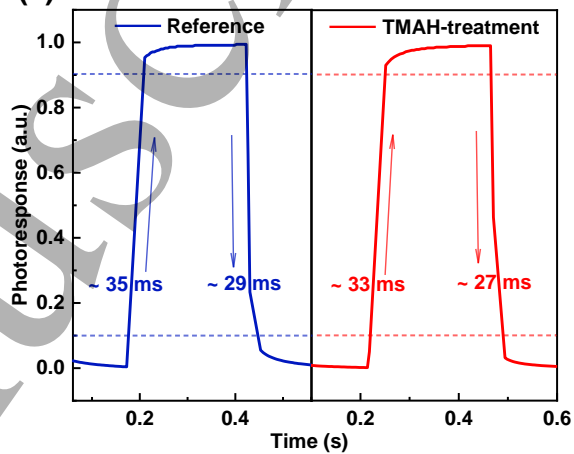

Figure 3. (a) The I-V curves of the AlGaN nanowire PDs with and without TMAH passivation under dark and $265 \mathrm{~nm}$ UV light illumination (the power density is $3.75 \mathrm{~mW} \mathrm{~cm}^{-2}$ ). The inset/shows the device under test. (b) Time-dependent photoresponse characteristics of the reference and TMAH-treated AlGaN PDs under $-4 \mathrm{~V}$ bias with the light power density of $3.75 \mathrm{~mW} \mathrm{~cm}^{-2}$. (c) Enlarged curves of a single cycle of the normalized photoresponse curves.

To understand the effect of surface passivation on the fundamental carrier dynamics after photoexcitation, we carried out the room temperature TRPL measurement on the reference and passivated AlGaN NWs, as shown in figure 4.

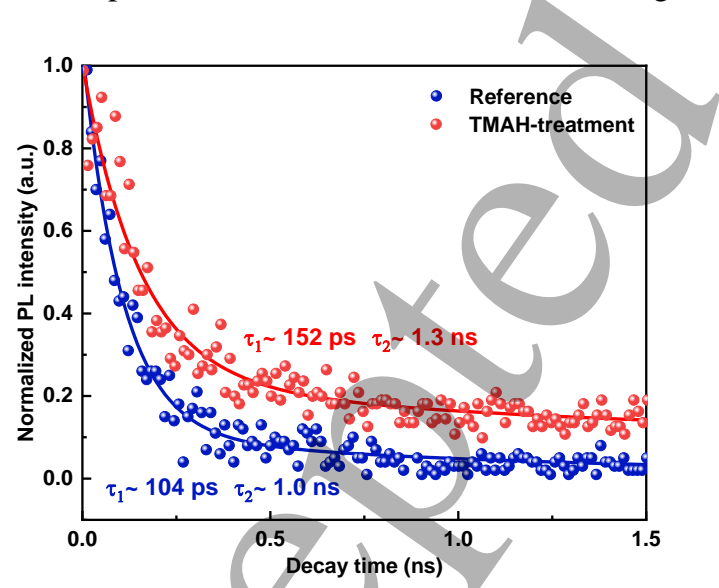

Figure 4. TRPL carrier lifetimes of the untreated and TMAHpassivated $\mathrm{AlGaN}$ NWs. The fast and slow decay time constants $\left(\tau_{1}\right.$ and $\left.\tau_{2}\right)$ are indicated in the figure.

Through biexponential decay fitting process, we observe that the fast and slow decay time constants $\left(\tau_{1}\right.$ and $\left.\tau_{2}\right)$ of reference NWs are 104 and $1067 \mathrm{ps,}$, while those of TMAHtreated NWs were 152 and $1262 \mathrm{ps,} \mathrm{respectively.} \mathrm{The} \mathrm{fast}$ decay component can be attributed to the trapping of surface states, and the slow decay component comes from the carrier relaxation of deep defect states. Therefore, the obtained larger $\tau_{1}$ in the treated devices suggests that the TMAH treatment reduced nonradiative recombination centers at nanowire surface and renders more time to collect and transport photogenerated carriers in the PDs [11,24].

We further implemented the XPS measurements to explore the element variations of the $\mathrm{AlGaN} \mathrm{NWs}$ after surface passivation. All binding energies were calibrated based on the $\mathrm{C} 1 \mathrm{~s}$ peak position $(284.8 \mathrm{eV})$. Presented in figure 5(a) are the captured $\mathrm{Al} 2 \mathrm{p}$ spectra for reference and TMAHpassivated AlGaN NWs. Based on the combination of Gaussian and Lorentzian fitting, the $\mathrm{Al} 2 \mathrm{p}$ peak can be deconvoluted into two contributions of Al-N bond at $73.0 \mathrm{eV}$ and $\mathrm{Al}-\mathrm{O}$ bond at $74.2 \mathrm{eV}$, respectively. Noticeably, after TMAH passivation, the ratio of the normalized concentration of Al-O bond to that of $\mathrm{Al}-\mathrm{N}$ bond (ratio of $\mathrm{Al}-\mathrm{O} / \mathrm{Al}-\mathrm{N}$ ) has reduced from $40.4 \%$ to $20.7 \%$. A similar decreasing trend of the oxide-related peak was observed in the captured $\mathrm{Ga} 3 \mathrm{~d}$ spectra as well. As shown in figure 5(b), the Ga $3 \mathrm{~d}$ peak can be deconvoluted into three contributions of Ga-N bond at 
$19.4 \mathrm{eV}, \mathrm{Ga}-\mathrm{O}$ bond at $20.4 \mathrm{eV}$, and $\mathrm{N} 2 \mathrm{~s}$ at $15.8 \mathrm{eV}$. The calculated ratio of $\mathrm{Ga}-\mathrm{O} / \mathrm{Ga}-\mathrm{N}$ of $24.5 \%$ in the passivated sample is relatively lower than that of $41.9 \%$ in the reference sample, indicating the effective removal of surface oxides via TMAH passivation [25-27]. Our XPS observations in regards to the reduction of oxygen-related complex on nanowire's surface are consistent with a report where they confirmed the disappearance of oxygen atoms on the nanowire's surface by using a detailed chemical mapping on nitrides NWs after surface passivation treatment [28].
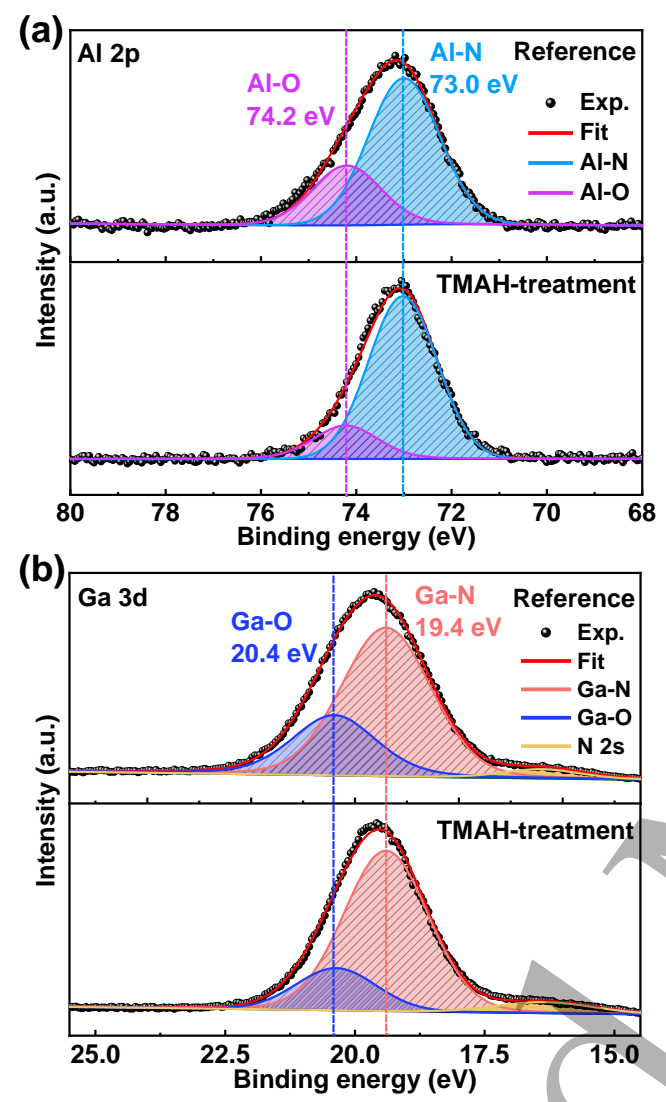

Figure 5. (a) $\mathrm{Al} \mathrm{2p}$ and (b) Ga 3d core levels of the AlGaN nanowire surfaces before and after TMAH passivation.

In order to confirm that the passivated devices are quantitatively dependent on the external illumination intensity, the time-dependent photoresponse under different illumination power density is presented in figure 6(a). The measured photocurrent as a function of light power density is plotted in figure 6(b) (red squares), in which the photocurrent

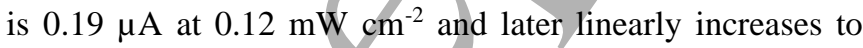
$3.21 \mu \mathrm{A}$ at $3.75 \mathrm{~mW} \mathrm{~cm}^{-2}$. Such linear behavior can be explained by the fact that photoexcited electron-hole pairs are effectively separated and can scarcely be captured by trap states [29]. Additionally, we observed the value of $R$ varying sensitively to different incident light power densities, as in figure 6(b) (orange circles), indicating its excellent photodetection ability. We further compare our device performance with other early reported AlGaN nanowire/nanorod based UV PDs, as presented in Table 1, and find that our proposed TMAH-treated AlGaN NWs (not including GaN NWs) shows ever-reported highest $R$, revealing the great potential of such effective and environmentally-friendly passivation method in the pursuit of high-efficiency nanowire-based UV photodetection.
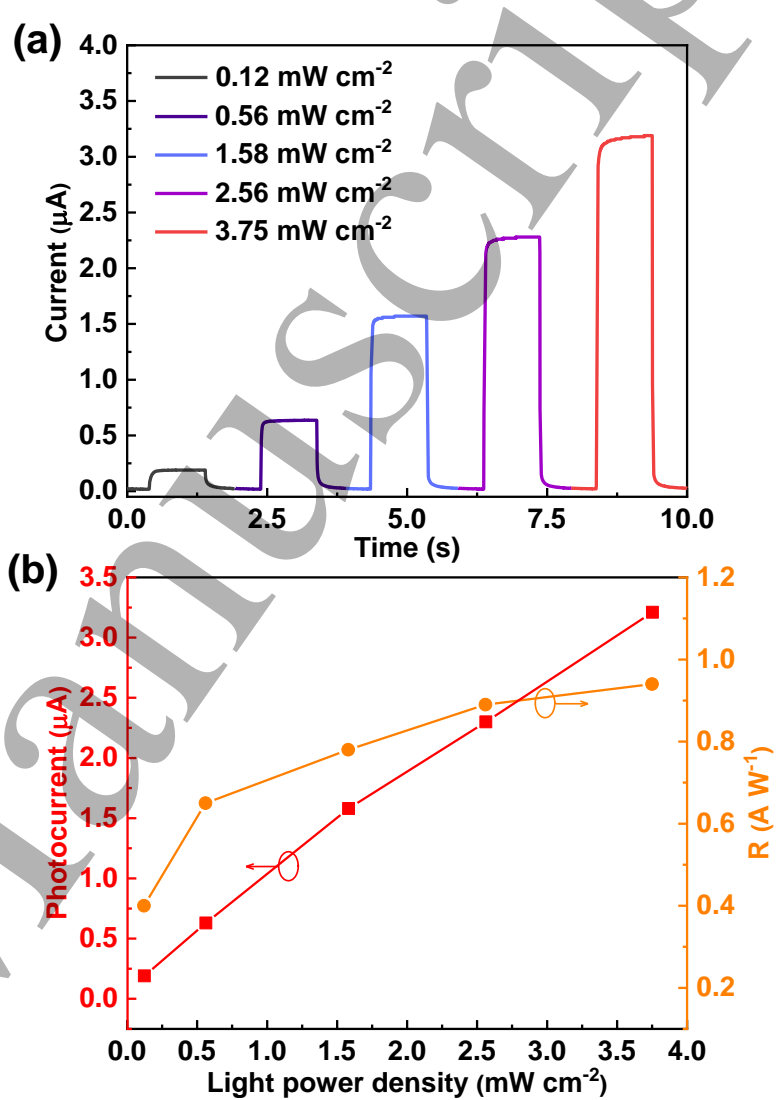

Figure 6. (a) Photocurrent of the TMAH-passivated device under $-4 \mathrm{~V}$ bias with the incident light power density of 0.12 , $0.56,1.18,2.56$, and $3.75 \mathrm{~mW} \mathrm{~cm}^{-2}$, respectively. (b) Fitting curve and corresponding calculated responsivity of the TMAH-passivated device under different light power density. 
Table 1. Detailed comparison between previously reported AlGaN nanowire-based PDs with our current AlGaN quantumdisk nanowire PDs with or without TMAH passivation.

\begin{tabular}{|c|c|c|c|c|c|}
\hline AlGaN structure & $R\left(\mathrm{~A} \mathrm{~W}^{-1}\right)$ & $\begin{array}{c}\text { Dark current } \\
\text { (A) }\end{array}$ & $\begin{array}{l}\text { Rise/decay } \\
\text { time (ms) }\end{array}$ & $\begin{array}{c}\text { Detectivity } \\
\text { (Jones) }\end{array}$ & Referer \\
\hline $\begin{array}{l}\text { AlN } p \text { - } i \text { - } n \text { quantum- } \\
\text { disk nanowires }\end{array}$ & $\begin{array}{l}\sim 0.001 \\
(-6 \mathrm{~V})\end{array}$ & $\sim 10^{-10}$ & - & $\sim 0.2 \times 10^{11}$ & \\
\hline AlGaN nanorods & $0.12(3 \mathrm{~V})$ & - & - & - & 87 \\
\hline AlGaN nanoflowers & $0.72(2 \mathrm{~V})$ & - & - & $4.76 \times 10^{7}$ & 30 \\
\hline $\begin{array}{l}\text { AlGaN nanowires } \\
\text { with graphene } \\
\text { electrode }\end{array}$ & $0.18(-2 \mathrm{~V})$ & $5.4 \times 10^{-8}$ & $4000 / 4700$ & & 31 \\
\hline $\begin{array}{c}\text { AlGaN/AlGaON } \\
\text { nanowires }\end{array}$ & $0.73(-5 \mathrm{~V})$ & $10^{-4}$ & . & & 32 \\
\hline $\begin{array}{c}\text { AlGaN } p-i-n \\
\text { quantum-disk } \\
\text { nanowires (as-grown) }\end{array}$ & $0.83(-4 \mathrm{~V})$ & $7.23 \times 10^{-8}$ & & $.6 \times 10^{11}$ & This work \\
\hline $\begin{array}{c}\text { AlGaN } p-i-n \\
\text { quantum-disk } \\
\text { nanowires (TMAH- } \\
\text { treated) }\end{array}$ & $0.95(-4 \mathrm{~V})$ & $6.22 \times 10^{-9}$ & & $6.4 \times 10^{11}$ & This work \\
\hline
\end{tabular}

\section{Summary and conclusions}

In conclusion, we have demonstrated that the TMAH wet chemical treatment is a promising method to boost the electrical and optical performance of $\mathrm{AlGaN}$ nanowire UV PDs. By introducing the TMAH surface passivation, the dark current was reduced from $7.23 \times 10^{-8} \mathrm{~A}$ to $6.22 \times 10^{-9} \mathrm{~A}$ in the $\mathrm{AlGaN}$ nanowire PDs, leading to the enhancement in $P D C R$, $R$, and $D^{*}$. We attribute the reasons to the reduction of nonradiative recombination centers originated from surface oxides and states. This work provides/an effective and convenient method to realize low-dark-current and highresponsivity AlGaN nanowire UV PDs.

\section{Acknowledgements}

This work was funded by National Natural Science Foundation of China (Grant No. 61905236, 51961145110), Fundamental Research Funds for the Central Universities
(Grant No. WK2100230020), USTC Research Funds of the Double First-Class Initiative (Grant No. YD3480002002), and was partially carried out at the USTC Center for Micro and Nanoscale Research and Fabrication.

\section{ORCID iDs}

Chen Huang https://orcid.org/0000-0003-3350-0805

Haiding Sun https://orcid.org/0000-0001-8664-666X

\section{References}

[1] Wang D, Liu X, Kang Y, Wang X, Wu Y, Fang S, Yu H, Memon M H, Zhang H, Hu W, Mi Z, Fu L, Sun H and Long S 2021 Nat. Electron. 4645

[2] Wang D, Liu X, Fang S, Huang C, Kang Y, Yu H, Liu Z, Zhang H, Long R, Xiong Y, Lin Y, Yue Y, Ge B, Ng T K, Ooi B S, Mi Z, He J H and Sun H 2020 Nano Lett. 21120

[3] Xie C, Lu X T, Tong X W, Zhang Z X, Liang F X, Liang L, Luo L B and Wu Y C 2019 Adv. Funct. Mater. 291806006 
[28] Khan J I, Adhikari A, Sun J, Priante D, Bose R, Shaheen

[4] Zhang H, Huang C, Song K, Yu H, Xing C, Wang D, Liu Z and Sun H 2021 Rep. Prog. Phys. 84044401

[5] Huang C, Zhang H and Sun H 2020 Nano Energy 77105149.

[6] Cai Q, You H, Guo H, Wang J, Liu B, Xie Z, Chen D, Lu H, Zheng Y and Zhang R 2021 Light Sci. Appl. 1094

[7] Aiello A, Wu Y, Mi Z and Bhattacharya P 2020 Appl. Phys. Lett. 116061104

[8] Kang S, Chatterjee U, Um D Y, Yu Y T, Seo I S and Lee C R 2017 ACS Photonics 42595

[9] Sun H, Priante D, Min J W, Subedi R C, Shakfa M K, Ren Z, Li K H, Lin R, Zhao C, Ng T K, Ryou J H, Zhang X, Ooi B S and Li X 2018 ACS Photonics 53305

[10] Zulkifli N A, Park K, Min J W, Ooi B S, Zakaria R, Kim J and Tan C L 2020 Appl. Phys. Lett. 117191103

[11] Zhao S, Woo S Y, Bugnet M, Liu X, Kang J, Botton G A and Mi Z 2015 Nano Lett. 157801

[12] Tran N H, Le B H, Zhao S and Mi Z 2017 Appl. Phys. Lett. 110032102

[13] Djavid M and Mi Z 2016 Appl. Phys. Lett. 108051102

[14] Perraud S, Poncet S, Noel S, Levis M, Faucherand P, Rouviere E, Thony P, Jaussaud C and Delsol R 2009 Sol. Energy Mater. Sol. Cells 931568

[15] Nguyen H P T, Cui K, Zhang S, Djavid M, Korinek A, Botton G A and Mi Z 2012 Nano Lett. 121317

[16] Janjua B, Sun H, Zhao C, Anjum D H, Wu F, Alhamoud A A, Li X, Albadri A M, Alyamani A Y, El-Desouki M M, Ng T K and Ooi B S 2017 Nanoscale 97805

[17] Zhao C, Ng T K, Prabaswara A, Conroy M, Jahangir S, Frost T, O'Connell J, Holmes J D, Parbrook P J, Bhattacharya P, and Ooi B S 2015 Nanoscale 716658

[18] Chen X, Xia N, Yang Z, Gong F, Wei Z, Wang D, Tang J, Fang X, Fang D and Liao L 2018 Nanotechnology 29095201

[19] Sun H, Shakfa M K, Muhammed M M, Janjua B, Li K H, Lin R, Ng T K, Roqan I S, Ooi B S and Li X 2017 ACS Photonics 5964

[20] Bui H Q T, Velpula R T, Jian B, Philip M R, Tong H D, Lenka T R and Nguyen H P T 2020 Appl. Opt. 597352

[21] Zhang Y, Sun M, Wong H Y, Lin Y, Srivastava P, Hatem C, Azize M, Piedra D, Yu L, Sumitomo T, de Almeida Braga N, Mickevicius R V and Palacios T 2015 IEEE Trans. Electron Devices 622155

[22] He J, Feng M, Zhong Y, Wang J, Zhou R, Gao H, Zhou Y, Sun Q, Liu J, Huang Y, Zhang S, Wang H, Ikeda M and Yang H 2018 Sci. Rep. 87922

[23] Luo L B, Hu H, Wang X H, Lu R, Zou Y F, Yu Y Q and Liang F X 2015 J. Mater. Chem. C 34723

[24] Varadhan P, Fu H C, Priante D, Retamal J R, Zhao C, Ebaid M, Ng T K, Ajia I, Mitra S, Roqan I S, Ooi B S and He J H 2017 Nano. Lett. 171520

[25] Zhong Y, Zhou Y, Gao H, Dai S, He J, Feng M, Sun Q, Zhang J, Zhao Y, DingSun A and Yang H 2017 Appl. Surf. Sci. 420817

[26] He J, Zhong Y, Zhou Y, Guo X, Huang Y, Liu J, Feng M, Sun Q, Ikeda M and Yang H 2019 Appl. Phys. Express 12 055507

[27] Huang R, Liu T, Zhao Y, Zhu Y, Huang Z, Li F, Liu J, Zhang L, Zhang S, Dingsun A and Yang H 2018 Appl. Surf. Sci. 440637

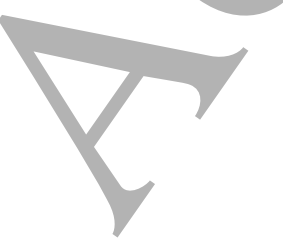
B S, Ng T K, Zhao C, Bakr O M, Ooi B S and Mohammed O F 2016 Small 122313

[29] Wang D, Huang C, Liu X, Zhang H, Yu H, Fang S, Ooi B S, Mi Z, He J H and Sun H 2020 Adv. Opt. Mater. 2000893

[30] Kang S, Nandi R, Kim H, Jeong K U and Lee C R, $2018 \mathrm{~J}$. Mater. Chem. C 61176

[31] Zhou M, Qiu H, He T, Zhang J, Yang W, Lu S, Bian L and Zhao Y 2020 Phys. Status Solidi A 2000061

[32] Zhang X, He T, Tang W, Ma Y, Wei X, Wang D, Zhang H, Sun H, Fan Y, Cai Y and Zhang B 2020 J. Phys. D: Appl. Phys. 53495105 